Ciência e Natura, Santa Maria v.38 n.2, 2016, Mai.- Ago. p. 966 -979

Revista do Centro de Ciências Naturais e Exatas - UFSM

ISSN impressa: 0100-8307 ISSN on-line: 2179-460X

\title{
CIÊNCIA'NATURA
}

\section{ICMS ecológico como ferramenta de proteção ambiental: análise da aplicação no estado do Rio Grande do Sul}

\author{
ICMS ecological as a tool of environmental protection: implementing the analysis in Rio \\ Grande do Sul state
}

\author{
Pâmela Muriel Aude Lovatto e Jefferson Marçal Rocha \\ Universidade Federal do Pampa, São Gabriel, Brasil \\ pamela.aude@hotmail.com; jeffersonmrocha@gmail.com
}

\begin{abstract}
Resumo
Este artigo tem por objetivo analisar a aplicação do ICMS - Ecológico no Estado do Rio Grande do Sul. O ICMS Ecológico trata-se do instrumento econômico ligado ao sistema tributário estadal direcionado à proteção ambiental. Nos últimos anos ocorreu uma disseminação da política pública de uso do ICMS ecológico nos mais diversos estados brasileiros. Para realizar a pesquisa foi feita uma análise das propostas de aplicação do ICMS Ecológico no Estado do RS comparando com os demais estados do Brasil. Pela análise verificou-se que houve a conjunção entre o métodos e os critérios de distribuição do imposto no RS, bem como a atual repartição entre os municípios, identificando-se também os recebedores dos maiores e menores valores. Constatou-se que a origem deste imposto é eminentemente extrafiscal e seu propósito é que os municípios resguardem sua biodiversidade já existente e incentive-os a criação de novas áreas verdes, através da utilização desses royalties. Os resultados encontrados comprovam que os municípios que recebem estes royalties são aqueles que possuem unidades de conservação, mas muitos municípios que também possuem este tipo de reserva não são contemplados, talvez porque desconheçam a legislação.
\end{abstract}

Palavras-chave: Instrumento Econômico.Política Pública. Proteção dos Recursos Naturais.

\begin{abstract}
This article aims to analyze the application of the ICMS - Ecological State of Rio Grande do Sul - RS. The Ecological ICMS it is the used economic instrument and connected to the tax system directed to environmental protection. In recent years there has been a spread of public policy for the use of ecological ICMS in several states. To conduct the survey was made an analysis of the ICMS investment proposals - Ecological RS in the state compared to other states of Brazil. She smoothed the method and the tax distribution criteria in the RS, as well as the current distribution between the cities and to identify the recipients of the highest and lowest values. It was found that the origin of this tax is eminently extrafiscal and its purpose is that municipalities will safeguard its existing biodiversity and encourage them to create new green spaces through the use of these Royalties. The results show that the municipalities receiving these Royalties are those with protected areas, but many municipalities that also have this type of reservation are not covered, perhaps because they are unaware of the legislation.
\end{abstract}

Keywords: Economic Instrument. Public Policy. Protection of Natural Resources. 


\section{Introdução}

O ICMS Ecológico no Brasil tem por finalidade incentivar os municípios a buscarem medidas de preservação e conservação, e para que isto se concretize, a distribuição dos valores é feita de forma proporcionalmente crescente, ou seja, quanto mais extensa a área verde maior será o valor percentual a este destinado (GOMES, 2009).

Dezessete Estados brasileiros já implantaram o ICMS Ecológico apesar disso, ainda não há uniformidade nestes projetos, uma vez que a legislação deste tributo permite variâncias, tanto na implantação como na aplicação dos recursos. Por definição o ICMS Ecológico é o critério ou conjunto de critérios, voltados para a busca de soluções para os problemas ambientais. Estes critérios são utilizados para a determinação do "quanto" cada município vai receber na repartição dos recursos financeiros, arrecadados com o Imposto sobre Circulação de Mercadorias e Serviços o ICMS (GOMES, 2009).

Esta pesquisa analisa o aprimoramento do uso do ICMS - Ecológico no Estado do RS, considerando que este é uma ferramenta econômica aplicada ao sistema tributário, que tem como objetivo a proteção dos recursos naturais e, se bem aplicado, poderá implementar um mecanismo de estímulo a proteção e preservação dos recursos naturais.

\section{Referencial Teórico}

\subsection{ICMS Ecológico}

Na Constituição Federal Brasileira de 1988 os tributos estão elencados no artigo 145, classificam-se as espécies de tributo em: impostos, taxas e contribuições de melhoria. Ainda existem duas espécies: os "Empréstimos Compulsórios", regulados pelo artigo 148 da Constituição Federal e as "Contribuições Sociais", regidas pelos artigos 149 e 195 do mesmo diploma legal.

A Carta Magna das leis brasileiras no seu artigo 158 do capítulo IV, a fim de garantir autonomia financeira aos municípios, assegurou que vinte e cinco por cento (25\%) do imposto sobre operações relativas à circulação de mercadorias e sobre prestações de serviços de transporte interestadual, intermunicipal e de comunicação (ICMS) seria destinado a gestão municipais, desta forma o incentivo era que ocorresse à descentralização dos recursos públicos e uma distribuição sobre as áreas que mais fossem necessárias.

A partir deste princípio nasceu o ICMS Ecológico tendo por finalidade a compensação dos municípios por preservarem locais protegidos (unidades de conservação e outras áreas de preservação específicas), posto que isso pudesse servir de incentivo à restrição de determinados tipos de expansão (seja econômica como territorial urbana), ou seja, é um incentivo e bonificação, quanto mais área preservada maior seria o valor arrecadado. Obviamente percebe-se que o ICMS ecológico é do que um instrumento de política pública ambiental preservacionista.

Tem-se, por exemplo, o modelo do Paraná, citado por Loureiro (2010): “O ICMS Ecológico 
contribuiu para a melhoria da conservação da biodiversidade no Estado do Paraná, em especial quando combinado com outros instrumentos de política pública ou em parceria entre entes federados, em especial os próprios municípios beneficiados (LOUREIRO, 2010, p.151)."

Por haver esta autonomia estados e/ou municípios, cada ente federado criou sua própria legislação e forma de distribuição, conforme parâmetros que abrangessem sua necessidade local para melhoria da gestão de seus recursos, e diante dos vários aspectos ambientais cada estado tenta se adequar em função do potencial e carências existentes. Neste contexto, surgiu uma forma de incentivo importante para manutenção dos ecossistemas municipais (LOUREIRO, 2002).

\subsection{O ICMS-E NA LEGISLAÇÃO FEDERAL}

Na Constituição Federal, artigo 155, II e parágrafo $2^{\mathrm{o}}$ prevê as competências do ICMS para os Estados e Distrito Federal. Portanto, os Estados regulamentam a incidência, o pagamento, recebimento e o cálculo para efetuar a arrecadação do imposto. Quanto a sua distribuição, o Inciso IV do Artigo 158 da CF destina aos municípios 25\% do ICMS arrecadado, que devem ser distribuídos mediante os seguintes critérios segundo o inciso II do referido artigo: $75 \%$ na proporção do valor adicionado nas operações relativas à circulação de mercadorias e nas prestações de serviços, realizadas em seus territórios; até $25 \%$, de acordo com o que dispuser lei estadual ou, no caso dos Territórios, lei federal.
A viabilidade de criação do ICMS-E é aberta pelo Inciso II, cabendo a cada Estado definir regras e procedimentos para o repasse através de legislação estadual.

A regra que se refere ao comprometimento dos $3 / 4$ dos recursos de acordo com o critério do valor adicionado, como exemplo, se um município isoladamente é responsável por 10\% da arrecadação do ICMS no Estado, ele terá direito a $10 \%$ do volume de recursos repassados, Rocco (2004 apud Hempel, 2006, p11.) nos mostra que “é concentradora de renda, pois prioriza o repasse dos recursos para os municípios mais ricos, o que faz aumentar sua concentração de riquezas e a distância entre municípios ricos e pobres".

Nesse sentido, Scaff e Tupiassu (2005 apud Hempel, 2006, 11p.) assim se posicionam:

[...] os municípios que se dedicam ao desenvolvimento econômico em detrimento da preservação ambiental são aquilatados com maior quantidade de repasses financeiros, pois têm mais possibilidade de gerar receitas em função da circulação de mercadorias. Por outro lado, aqueles que arcam com a responsabilidade de preservar o bem natural, trazendo externalidades positivas que beneficiam a todos, têm restrições em sua capacidade de desenvolvimento econômico e, conseqüentemente, recebem menos repasses financeiros por contarem com uma menor circulação de mercadorias e serviços. Esta lógica necessariamente deve ser alterada, pois não dá conta da dinâmica da realidade e, principalmente, não se conforma com a proteção constitucional conferida ao meio ambiente [...].

Neste contexto destaca-se a Emenda Constitucional no42 de 2003, que coloca a defesa do meio ambiente como princípio geral da ordem econômica, prevendo o tratamento diferenciado conforme impacto ambiental de produtos e serviços e de seus processos de elaboração e prestação. 
É neste âmbito que se insere a filosofia do ICMS-E, pautada no Principio do ProtetorRecebedor. Tendo duas funções primordiais: a compensatória e a incentivadora.

No estudo realizado nota-se, que de um modo geral, o que mais aparece no ICMS Ecológico são as Unidades de Conservação. Porém, em relação às demais áreas protegidas aparecem: Unidades de
Conservação (todas as categorias), RPPNs (Reserva Particular de Patrimônio Natural), Terras Indígenas, APPs, Reserva Legal, Faxinais. Como indicado na tabela abaixo ilustra o fator de conservação estipulado para cada categoria de UC's.

\begin{tabular}{|c|c|}
\hline Critérios Adotados & Estados \\
\hline Unidades de Conservação & $\begin{array}{l}\text { Minas Gerais, Pernambuco, Mato Grosso } \\
\text { do } \\
\text { Sul, Amapá, Rio Grande do Sul, Tocantins, }\end{array}$ \\
\hline Terras Indígenas & $\begin{array}{l}\text { Paraná, Mato Grosso, Mato Grosso do Sul, } \\
\text { Tocantins e Piauí. }\end{array}$ \\
\hline Mananciais de Abastecimento & $\begin{array}{l}\text { Paraná, Mato Grosso do Sul, Tocantins e } \\
\text { Piauí. }\end{array}$ \\
\hline $\begin{array}{l}\text { Reservatórios para produção de energia } \\
\text { elétrica }\end{array}$ & São Paulo. \\
\hline Saneamento Ambiental & Minas Gerais, Tocantins e Pernambuco. \\
\hline Qualidade da Água & Rio de Janeiro. \\
\hline Gestão de Resíduos Sólidos & Rio de Janeiro, Piauí e Ceara. \\
\hline Educa & Pernambuco e Ceará. \\
\hline Educação Ambiental & Piauí \\
\hline Saúde & Pernambuco e Ceará. \\
\hline Conservação do Solo & Tocantins e Piauí. \\
\hline Reflorestamento & Piauí. \\
\hline Políticas Municipais de Meio Ambiente & Tocantins e Piauí. \\
\hline Controle de queimadas e combate a & Tocanti \\
\hline
\end{tabular}

(Fonte: Portal ICMS Ecológico).

\subsection{O ICMS-E NA LEGISLAÇÃO}

\section{ESTADUAL - RS}

Segundo a Secretaria da Fazenda do Rio Grande do Sul - SEFAZ-RS (2010), as principais fontes normativas do ICMS para o Estado são as seguintes:
- Artigo 155, II e parágrafo 2º ${ }^{\circ}$ da Constituição Federal prevê a competência do ICMS para os Estados e Distrito Federal;

- Leis Complementares no 87, de 1996 e 102, de 2000, definem as normas gerais do ICMS; - Lei estadual $\mathrm{n}^{\mathrm{o}}$ 8.820/89, institui o ICMS no Estado do Rio Grande do Sul;

- Decreto no 37.699, de 1997, Regulamento do ICMS atualmente em vigor; 
Instrução Normativa do Departamento da Receita Pública IN DRP $\mathrm{n}^{\mathrm{o}}$ 45/98, detalha a legislação, dando interpretações e instruções mais minuciosas aos contribuintes e à Administração Pública sobre o ICMS.

- A Lei Estadual 11.038/97 regula a distribuição do ICMS no Rio Grande do Sul, estabelecendo os critérios para tal.

No caso do Rio Grande do Sul, a compensação ambiental está incluída nos 7\% destinados ao critério Área Municipal. Menciona-se compensação, pois ainda não há critérios qualitativos que poderiam incentivar a melhoria na gestão ambiental das Unidades de Conservação UC's.

O inciso III do Art. $1^{\text {o }}$ da Lei Estadual 11.038/97 dispõe sobre a fórmula do cálculo para distribuição do ICMS Ecológico no RS qual seja: 7\% (sete por cento) com base na relação percentual entre a área do município, multiplicando-se por 3 (três) as áreas de preservação ambiental e aquelas inundadas por barragens, exceto as localizadas nos municípios sedes das usinas hidrelétricas, e a área calculada do Estado, no último dia do ano civil a que se refere a apuração, informadas, em quilômetros quadrados, pela Divisão de Geografia e Cartografia da Secretaria da Agricultura e Abastecimento do Estado - SAA (Rio Grande do Sul, 1997).

A PORTARIA N 252/98 da SAA - RS define fatores de conservação das UC'S, com variação de 0,1a 1,0 a partir das respectivas restrições de uso e categoria de manejo de acordo com a Lei n. ${ }^{\circ}$ 9.985/2000.
Estes fatores devem ser considerados para obtenção da área de preservação a ser utilizada no cálculo da parcela do produto da arrecadação do ICMS-E pertencente aos municípios. Há, neste critério um fator qualitativo no que diz respeito à utilização da área da UC, o que confere maior coerência ao processo de compensação, visto que atribuí ponderações em relação à classificação da categoria de UC, de acordo com o Art. 12 do Decreto Estadual 38.814/98 através de notas denominadas fatores de conservação.

Sendo notas de 0,1 até 0,5 os fatores de conservação das unidades de manejo sustentado/categoria de uso direto, que são aquelas, cujo objetivo básico é promover e assegurar o uso sustentado do ambiente. Os fatores de conservação vão de 0,7 a 1 quando vinculados as unidades de proteção integral/categoria de uso indireto, que por sua vez são aquelas cujo objetivo básico é a preservação ambiental permitindo, tão somente, o uso indireto do ambiente, salvo as exceções legais.

Desta forma os municípios que possuem uma área de Reserva Biológica receberão um repasse do ICMS-E maior, que um que possui uma Área de Proteção Ambiental.

\subsection{MEDIDAS IMPLANTADAS EM OUTROS ESTADOS}

Para uma melhor compreensão de como implementado o ICMS Ecológico, segue um mapa explicativo de quais estados já possuem legislação disciplinando seu uso. 


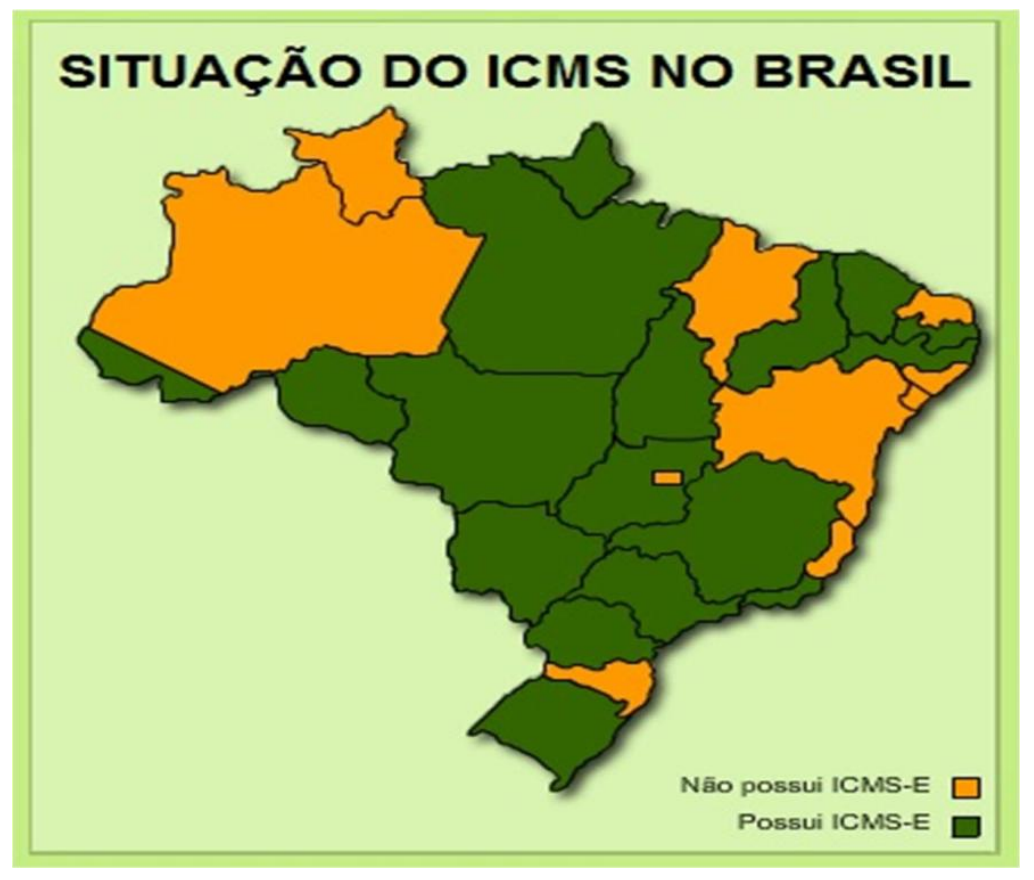

Fonte: Portal ICMS Ecológico, agosto de 2015.

\section{Paraná:}

Foi o estado pioneiro na implementação e arrecadação do imposto, possui legislação desde 1991 e, para base de cálculo, as áreas consideradas são: Unidades de Conservação, Áreas de Terras Indígenas, Faxinais, Áreas de Preservação Permanente e Reserva Florestal Legal. Encontra regulamentação no Decreto Estadual no 2.791, de 27 de dezembro de 1996, que apresenta o detalhamento matemático dos percentuais a serem repassados, sempre visando o incentivo aos proprietários das Reservas de Particular do Patrimônio Natural RPPN, nos termos da Lei 9.985/00.

\section{São Paulo:}

O segundo estado a aderir foi São Paulo,

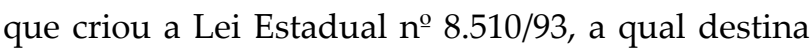
$0,5 \%$ dos recursos arrecadados para suas áreas protegidas. Diferentemente do Paraná, este estado não apresenta o componente qualitativo quanto ao manejo e qualidade da UC no cálculo do índice ecológico, assemelhando-se a forma de distribuição do Rio Grande do Sul, ou seja, consiste em uma mera estimativa de preservação. Outra característica do modelo paulista considera apenas as UC's Estaduais para a cota de ICMS Ecológico e não os particulares.

\section{Minas Gerais:}

No estado de Minas Gerais, 25\% destinados aos municípios correspondem ao Fator Ambiental, sua previsão esta no art. 1º, VIII da Lei 13.803/00. A supra lei determina que no máximo $50 \%$ do total será distribuído aos municípios com sistemas de tratamento ou final de lixo ou esgoto sanitário, com operação licenciada pelo órgão ambiental estadual, 
atendam, no mínimo, a, respectivamente $70 \%$ (setenta por cento) e a 50\% (cinquenta por cento) da população. No que tange ao restante é distribuído nos índices de conservações das UCs. Este estado inova, pois apresenta uma recompensa, a cada melhoria de vida alcançada, desta forma incentivando A saúde através de políticas de saneamento básico.

\section{Rondônia:}

O ICMS Ecológico em Rondônia está balizado na Lei Complementar Estadual 147 de 1996. Igualmente ao estado anterior, esta taxa possui caráter compensatório, e sua analise é feita calculando a relação de quantidade de e da UC em relação à área do município, tendo um caráter unicamente compensatório, dispensando qualquer outro fator, como por exemplo: nível de restrição da Unidade de Conservação. Segundo uma análise feita por GRIEG-GRAN (2000, apud João, 2004, p100.) após o início de vigência do ICMS Ecológico no Estado observou-se que, em suma, os municípios deste estado não possuem UCs e que a conservação da biodiversidade não está sendo feita de forma apropriada.

\section{Mato Grosso:}

No Mato Grosso, o ICMS - Ecológico tem sua base na LC Estadual $n^{\circ} 73$, de 2000. Ressalta-se que está meramente ligada, inicialmente a fatores quantitativos, a posterior passou a ter relevância os fatores qualitativos das UC'S e seu índice de distribuição é tal qual o estado de Minas Gerais, pois tem muitos anteriores.
Este estado apresenta uma característica muito interessante. Além do ICMS-Ecológico possuir legalidade na LC Estadual 1.530 de 2004, toda a gestão publica é através de uma Política de Desenvolvimento Sustentável, e esta já é utilizada a mais de 10 anos pelo Poder Executivo.

Com o surgimento do ICMS - Ecológico, houve a proteção e fortalecimento de 2,5 para 5,6 milhões de hectares por Unidades de Conservação. A implementação do valor do ICMS - Ecológico é progressiva anualmente, e inicia-se com 05\% do arrecadado, de acordo com dados obtidos no Portal ICMS Ecológico de agosto de 2015. Nota-se que se atribui maior percentual de repasse por critério ambiental.

\section{Pará:}

No ano de 2011, o estado implementou uma campanha denominada Municípios Verdes, dentre outras características esta o ICMS - Ecológico, seu projeto de LC estadual que o regulariza, encontra-se estagnado até o presente momento. Está lei prevê que a aplicação será anual e progressiva, com porcentagem por municípios de 8\%. Esses índices são de critério ecológico, serão calculados anualmente, de acordo com áreas protegidas no município.

\section{Amapá:}

O Amapá possui uma legislação desde 1996 (Lei Estadual no 322) a respeito do tema, porém esta não reconhece as categorias de UCs, o que está em desacordo com o Sistema Nacional de Unidades de Conservação - SNUC. Em consequência disto, em 2004, foi gerado um novo projeto de lei que se 
adequava aos padrões e isto veio a aumentar a participação do critério ambiental entre os demais índices.

Ressalta-se que a Legislação do Amapá é revestida por algo incomum, possui um anexo da lei a sua regulamentação, ou seja, não existe forma de detalhar o critério de calcular e distribuir, sendo que o anexo da lei define apenas como é a participação dos municípios e expõe a fórmula a ser adotadas.

\section{Mato Grosso do Sul:}

Este estado possui inúmeras regulamentações sobre o tema, começando no ano de 1991, e prosseguindo com a Lei Complementar

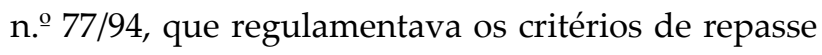
aos municípios, que possuíssem em seus territórios Unidades de Conservação ambiental. No ano de

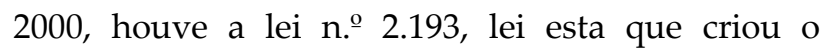
Cadastro Estadual de Unidades de Conservação e de mananciais de abastecimento público, com isto foram criados critérios técnicos de alocação dos recursos e os índices percentuais relativos a cada município.

Em 2004 foi criado O Programa Estadual do ICMS Ecológico, com a finalidade de efetivar esse conjunto de normas. Desta forma, os 25\% do ICMS destinados aos municípios, foram distribuídos assim: 7\% divididos igualitariamente entre todos os municípios; 5\% em função da extensão territorial do município; 5\% em virtude do número de eleitores; $3 \%$ conforme o índice resultante do percentual da receita própria e, por fim, 5\% o critério ambiental, a ser dividido entre os municípios que tenham parte de seu território integrando terras indígenas homologadas, unidade de conservação da natureza devidamente inscrita no Cadastro Estadual de Unidades de Conservação e, ainda, aos que possuam plano de gestão, sistema de coleta seletiva e disposição final de resíduos sólidos, devendo esta última, serem devidamente licenciada.

\section{Goiás:}

Esse estado aprovou a Emenda Constitucional n. ${ }^{-} 40$ de 2007, que previa a destinação de $5 \%$ dos recursos, passíveis de serem regulamentados por lei estadual para o ICMS Ecológico, mas somente em 2011 teve a Lei Complementar n. ${ }^{\mathrm{o}} 90$ que instituiu o ICMS Ecológico no estado, sua perspectiva é que os municípios passem a ser beneficiados pelos recursos do ICMS Ecológico da seguinte forma, dentro da partilha dos 5\%, 3\% para os municípios que possuírem gestão ambiental, desde que esta esteja conforme os padrões de desenvolvimento sustentável e de conservação dos recursos naturais; $1,25 \%$ para os municípios que já regulamentam e colocam em prática pelo menos quatro de nove providências estabelecidas no inciso I e 0,75\% para os municípios que já tenham regulamentado e colocado em prática pelo menos três das nove providências estabelecidas no inciso I.

\section{Tocantins:}

O ICMS - Ecológico foi instituído na Lei Complementar 1.323/02, possui além dos critérios já existentes nos demais estados, outros, tais quais: preocupação com a conservação da água e dos parques, além de bonificar municípios que possuam boas políticas de meio ambiente, controle de queimadas e combate a incêndios, promovam a 
conservação dos solos, atuem de forma direta ou indireta na distribuição de água potável, no tratamento do esgoto e da coleta e destinação final do lixo.

A dita lei possui um anexo e nele é estabelecida a porcentagem progressiva, levando em consideração a soma de todos os critérios. Eram eles: $3,5 \%$ para o ano de $2003 ; 6,5 \%$ para $2004 ; 8,5 \%$ para $2005 ; 12 \%$ para 2006 ; e $13 \%$ para 2007 . Observase que é maior que qualquer outro índice estadual. O Tocantins é o primeiro estado a analisar a conservação dos solos no ICMS - Ecológico.

\section{Rio de Janeiro:}

É o estado mais novo a possuir legislação sobre o ICMS - Ecológico, mas deve ser ressaltado que ainda não está regulamentada. Chamam-se ICMS Verde, trazido pela Lei $n^{\circ}$. 5.100/07. Seus índices são: 45\% para áreas conservadas (unidades de conservação, reservas particulares e áreas de proteção permanentes); 30\% para qualidade da água; e 25\% para a administração dos resíduos sólidos.

Uma coisa, porém deve ser parabenizada, o Rio de Janeiro apresenta um avanço em relação aos demais estados, as prefeituras que criarem suas próprias Unidades de Conservação terão direito a $20 \%$ dos $45 \%$ destinados à manutenção de áreas protegidas, Desta forma, o próprio município poderá aumentar seu valor ganho no repasse.

\section{Piauí:}

A Comissão de Constituição e Justiça (CCJ) em maio de 2008, aprovou a criação do ICMS Ecológico no Estado, mas este ainda não possui regulamentação e lei, com isto não pode ser fornecido dados critérios e distribuição.

\section{Paraíba:}

Este estado está ainda mais atrasado que o anterior, pois, está em fase de debates sobre a questão do ICMS - Ecológico. Porém, já foram promovidos alguns Seminários junto ao órgão oficial do meio ambiente para discussão do tema.

\section{Ceará:}

O ICMS-Ecológico foi aprovado da Lei Estadual n. ${ }^{\mathrm{o}}$ 14.023/07, regulamentado pelo Decreto Esta- dual no 29.306/08. O Estado do Ceará incorporou a metodologia utilizada pelo Programa Selo Município Verde no ICMS - Ecológico. Este programa tem tudo para ser um dos mais modernos, e trazer ainda mais benefícios ao Brasil, ocorre que ainda falta análise geral de dados sobre seu resultado.

\section{Pernambuco:}

O ICMS - Ecológico denomina-se neste estado como "ICMS Sócio-Ambiental". Foi aprovado pela Lei Estadual no 11.899/00, nela é destinados $12 \%$ a contar de 2003, porém destes aspectos $1 \%$ destina-se para os municípios que possuem unidades de conservação e 5\% devem ser distribuídos de forma igualitária aos municípios que possuam unidade de compostagem ou aterro sanitário controlado. O modelo de gestão do ICMS Ecológico através da biodiversidade deverá passar por um processo de crescimento que será aumentado no transcorrer dos próximos anos com a 
adoção das fórmulas de cálculo já consagradas em outros Estados.

\section{Método de Pesquisa}

A metodologia utilizada visa esclarecer a explicação da linha de trabalho, a abordagem escolhida para o trabalho, os métodos e as técnicas propostas. O tipo de pesquisa realizado para a elaboração deste trabalho foi à pesquisa exploratória, coletaram-se as informações, analisaram-se os dados, e apresentaram-se as análises referentes ao problema estudado. Para melhor desenvolvimento deste trabalho foram realizadas pesquisas bibliográficas e documentais.

O método de aplicação do ICMS ecológico, bem como a distribuição dos recursos do ICMS no RS foi obtido através de consultas realizadas junto à documentação disponível na página web da Secretaria da Fazenda (SEFAZ-RS) e do Meio Ambiente (SEMA-RS) do Estado do RS, e a Área de Receitas da Federação das Associações de Municípios do Rio Grande do Sul (FAMURS). Posteriormente comparou-se a realidade atual do Estado com a análise das experiências de outros Estados e da bibliografia levantada, seguido da formulação de análises que visam resultar em subsídios para posteriores propostas para o aprimoramento da aplicação do instrumento no Estado.

Para realizar uma apuração dos subsídios para elaboração de propostas para aplicação do ICMS - Ecológico no Estado do RS, analisou-se o método e os critérios de distribuição do imposto no
RS, bem como a atual repartição entre os municípios, identificando os recebedores dos maiores e menores valores.

\section{Análise dos Resultados}

O Método para distribuição do ICMS Ecológico no RS consiste na criação, por parte dos municípios de Unidades de Conservação, através de estudo técnico e de lei municipal, posteriormente cadastrando-as no Sistema Estadual de Unidades de Conservação (Decreto 34.256/92 e Decreto 38.814/98, que cria e Regulamenta o Sistema Estadual de Unidades de Conservação - SEUC, respectivamente). O órgão que gerencia o sistema é a Divisão de Unidades de Conservação do DEFAPSEMA. Este repassa as informações sobre a área ecológica calculada para a SEFAZ-RS que distribui o recurso aos municípios. Após a criação de UC's nos termos do Decreto 38.814/98, o retorno do ICMS aos municípios ocorre seguido da confirmação das informações, que são checadas mediante vistoria nas localidades.

As características da aplicação do ICMS Ecológico no Rio Grande do Sul foi obtida a partir da análise das Tabelas, referentes à Distribuição do ICMS proveniente do critério disposto no Inciso III do Art. 1o da Lei Estadual 11.038/97, que compreende a relação percentual entre a área do município, as áreas de preservação ambiental multiplicadas por três e área total do Estado.

Nestas tabelas encontram-se expressas a Área Total Municipal - pela qual o município recebe o repasse de recursos independente de sua área ecológica, e a Área Ecológica Municipal - área de 
UC's cadastrada e mananciais de abastecimento, estes multiplicados por 3. Seguido dos valores provenientes do ICMS recebido pela área total do município e adicional referente ao ICMS Ecológico.

Sendo o valor do repasse do ICMS Ecologico de cada município, refere-se ao percentual da participação deste município na Área Total Ecológica do Estado.

No ano de 2008, 124 municípios gaúchos recebiam o ICMS, que proporciona um significativo montante dos municípios do Estado, porém neste critério alguns municípios como Porto Xavier, Sinimbu, Seberi, entre outros não recebem nenhum valor, pois não possuem nenhuma área cadastrada de UC, mesmo sendo municípios com áreas preservadas.

Atualmente no Rio Grande do Sul, o repasse referente ao ICMS Ecológico tem sido através das áreas de UC's. A legislação gaúcha prioriza o aspecto compensatório do imposto, relegando ao segundo plano seu componente incentivador. A falta da incorporação de medidas pode ser uma das principais limitações do modelo do estado, onde os municípios poderiam investir em melhorias quanto à gestão das UC's caso houvesse incentivo financeiro.

As experiências vividas de outros estados podem servir de modelo para o Rio Grande do Sul, por exemplo: da experiência mineira pode-se aproveitar a questão do saneamento e coleta de resíduos e patrimônio cultural, possibilitando também incentivar a coleta seletiva. Da experiência paranaense destaca-se a questão do incentivo à conectividade florestal, e os critérios qualitativos quanto ao manejo da UC que vem ao encontro de princípios1 da Convenção da Biodiversidade (CDB), que foi ratificada pelo Decreto Legislativo No 2/94.

\begin{abstract}
As diretrizes orientam para que as ações principais se concentrem nas regiões de maior representatividade da biodiversidade, ou seja, a unidade de conservação, além dos corredores ecológicos, que estabelecem conexão entre elas.Estas propostas são fundamentais, pois abordam a conservação in situ da diversidade biológica. A operacionalização das atividades está prevista em projeto aprovado pelo Banco Mundial, a iniciar suas ações em abril de 2002 PARANÁ(2000, apud Loureiro,2002, p14.).
\end{abstract}

O Estado do Paraná editou em 1994 o Decreto Estadual n.o 4.262/94 que definiu no seu artigo $4^{\mathrm{o}}$ um conjunto de incentivos aos proprietários que destinarem voluntariamente porções de seus territórios à constituição de RPPN. Além disto, a Portaria n.o 232/98 do IAP, disciplina em seus artigos 8, 9 e 10, os procedimentos passíveis de serem adotados na relação: proprietário <-> municipalidade, quanto ao apoio desta ao proprietário, em função dos recursos financeiros angariados (Loureiro,2004, 10p.).

As medidas propostas para o Estado são aprimoramento da legislação, estudar a possibilidade de incorporar variáveis no que diz respeito à implementação de investimentos em saneamento. $\mathrm{O}$ caso referente às RPPN's no Paraná, por exemplo, teve estudo da obrigatoriedade de conectividade para incorporar áreas de preservação permanente e Reserva Legal na área ecológica municipal para o recebimento do ICMS-Ecológico.

A execução dessas políticas aumentaria o número das unidades de conservação e a qualidade da conservação destas. Assim possibilitando o avanço dos parâmetros socioambientais. Uma boa 
possibilidade poderia ser o ICMS-Ecológico como aumento da qualidade ambiental, em função da conservação do meio ambiente e sua biodiversidade, e o aumento dos recursos, tendo impacto benéfico nos investimentos em meio ambiente a ser praticado.

\section{Conclusão}

No RS estão explicitados os valores específicos do repasse do ICMS Ecológico por município, o que dificulta o controle e a motivação para os demais municípios. Falta transparência na política de implantação deste repasse e também uma atuação política mais competente dos prefeitos municipais. Comparando com os outros estados, verificou-se que são aqueles que mantêm uma área maior em relação ao percentual total da área do Estado, porém não há critérios que possam compensar aqueles municípios que possuem um manejo ecológico mais aprimorado, e que contribuem para preservação da biodiversidade do Estado de forma mais efetiva. Nos Estados que adotaram o ICMS Ecológico é visível a melhoria na qualidade de vida, bem como uma conscientização por parte da população para a manutenção do um meio ambiente.

Nos Estados que adotaram o critério Unidades de Conservação, com base na variável quantitativa e a qualitativa, houve um aumento considerável destas áreas protegidas, proporcionando também a conservação da biodiversidade ali existente.
Vários municípios já conseguem perceber as Unidades de Conservação como uma oportunidade de renda, e não como impedimento ao desenvolvimento. O ICMS Ecológico estimula o Município a investir na conservação e desestimula a degradação do meio ambiente. Para ser eficiente, o ICMS Ecológico, é indispensável que haja perseverança dos gestores públicos e um forte programa de conservação da biodiversidade investimentos e uma fiscalização. São fatores, atrelados à política, participação e cobrança da sociedade, que, consequentemente resultariam em fatores positivos de proteção ambiental.

No Estado do Rio Grande dos Sul, há muito para avançar. Como lemos junto ao portal da Transparência SEFAZ, a Receita Estadual "não dispõe de valores de repasse especificados por item componente da ponderação do índice, como é o caso do 'ICMS Ecológico' demandado.".

Destaca-se que, através do ICMS Ecológico, é que poderá aumentar as áreas protegido, assim como melhorar o manejo dessas, aliado à capacitação técnica de gestores ambientais, o aumento do número de municípios beneficiados e os investimentos municipais aplicados em gestão ambiental.

\section{Referências}

Brasil. Emenda Constitucional № 42, de 19 de dezembro de 2003. Altera o Sistema Tributário Nacional e dá outras providências.Disponível em: $<$ www.planalto.gov.br/ccivil.../emendas/.../emc42.ht m > Acesso em: 06 junho. 2015. 
Brasil. Decreto Legislativo $\mathrm{N}^{\circ} 2$, de 1994. Aprova o texto da Convenção sobre Diversidade Biológica; assinada durante a Conferência das Nações Unidas sobre Meio Ambiente e Desenvolvimento realizada na Cidade do Rio de Janeiro, no período de 5 a 14 de junho de 1992 . Disponível em: <http://www6.senado.gov.br/legislacao/ListaPublica coes.action?id=139068> Acesso em: 16 julho 2010.

Loureiro, W. Contribuição do ICMS ecológico à conservação da biodiversidade no Estado do Paraná. 2002. 189 f. Tese (Doutorado em Ciências Florestais) - Curso de Pós-Graduação em Engenharia Florestal, Universidade Federal do Paraná, Curitiba.

Loureiro, W. \& Martinez, A. ICMS Ecológico como instrumento de apoio as RPPN no Paraná. 2004. Disponível em:

$<$ www.icmsecologico.org.br/index.php?option=com _content\&view=article\&id=58\&Itemid=68> Acesso em: 08 setembro 2015.

Mato Grosso. Lei Complementar № 73, De 07 De Dezembro De 2000. Dispõe sobre os critérios de distribuição da parcela de receita do ICMS pertencente aos Municípios Disponível em:< http://app1.sefaz.mt.gov.br/sistema/legislacao/LeiCo mplEstadual.nsf/9733a1d3f5bb1ab384256710004d47 54/0034532ce0745d28042569b400641352?OpenDocu ment> Acesso em: 15 se. setembro 2015.

Minas Gerais. Deliberação Normativa COPAM n⿳ำ 86, de 17 de junho de 2005. Estabelece os parâmetros e procedimentos para aplicação do Fator de Qualidade, referente às unidades de conservação da natureza e outras áreas especialmente protegidas. Disponível em: < http://www.pdfgod.com/COPAMdoc.html> Acesso em: 19 setembro 2015.

Paraná. Decreto no 2.791, de 27 de dezembro de 1996. Define critérios técnicos a que alude o art. 5o da Lei Complementar no 59, de 01 de outubro de 1991.

Disponível em: <www.iap.pr.gov.br/meioambiente/arquivos/File/ia p/dec279196.pdf> Acesso em: 26 setembro. 2015.

Paraná. Decreto no 4.262 de 21 de novembro de 1994. Institui, no Território do Estado do Paraná, a Categoria de Manejo de Unidades de Conservação Denominada Reserva Particular do Patrimônio Natural - R.P.P.N., estabelecendo estímulos e incentivos a sua Implementação. Disponível em: < www.fazenda.pr.gov.br/UserFiles/File/decreto4262. pdf> Acesso em: 26 setembro. 2015.

Pernambuco. Lei n. 12206, de 20 de maio de 2002. Ajusta os critérios de distribuição de parte do ICMS que cabe aos Municípios relativamente aos aspectos socioambientais. DOE, mai 2002.

Rio Grande do Sul. Lei Estadual no 11.038, de 14 de Novembro de 1997. Dispõe sobre a parcela do produto da arrecadação do ICMS pertencente aos municípios. Disponível em:

<http://wwwhttp://www.mp.rs.gov.br/ambiente/legi slacao/id4712.htm> Acesso em: 09 out.2015. 
Rio Grande do Sul. DECRETO № 34.256, DE 02 DE ABRIL DE 1992. Cria o Sistema Estadual de Unidades de Conservação e dá outras providências. Disponível em: http://www.sema.rs.gov.br/sema/html/dec_34256.ht m> Acesso em: 09 out.2015.

Rio Grande do Sul Decreto Estadual n.ํㅜ 38.814, de 26 de agosto de 1998. Regulamenta o Sistema Estadual de Unidades de Conservação - SEUC e dá outras providências. Disponível em: $<$

http://www.mp.rs.gov.br/ambiente/legislacao/id559. htm> Acesso em: 09 out.2015.

Rondonia. Lei Complementar Estadual n 147, de 15 de janeiro de 1996. Disponível em: <www.portal.sefin.ro.gov.br/.../52.31394529513822L C96-147-ALT\%20LC115.pdf> Acesso em: 09 out.2015.

São Paulo. Lei Estadual no 8.510, de 29 de dezembro de 1993. Altera a LEI n.. 3201, de 23 de dezembro de 1981, que dispõe sobre a parcela, pertencente aos municípios, do produto da arrecadação do ICMS. Disponível em: <www.ambiente.sp.gov.br/.../estadual/leis/1993\%20 Lei\%208510.pdf $>$. Acesso em: 09 out.2015.

Scaff, F. F. E Tupiassu, L.V. da C. Tributação e Políticas Públicas: O ICMS Ecológico. In: TÔRRES, H. T. (Org.) Direito Tributário Ambiental. São Paulo, Malheiros Editores Ltda. 2005. 894 p
SEFAZ - RS. Secretaria da Fazenda do Estado do Rio Grande do Sul. Disponível em: $<$ http://www.sefaz.rs.gov.br>. Acesso em: 24 out. 2015.

Tocantins. Lei n. 1323 de 04 de abril de 2002. Dispõe sobre os índices que compõem o cálculo da parcela do produto da arrecadação do ICMS pertencente aos Municípios, e adota outras providências. DOE, abr 2002.

Hempel B. W. A Importancia Do Icms Ecológico Para Sustentabilidade Ambiental Disponível em: $<$ http://www.icmsecologico.org.br/site/images/artig os/a004.pdf> Acesso em: 05 novembro 2015.

SEFAZ - RS. Secretaria da Fazenda do Estado do Rio Grande do Sul. Disponível em: $<$ http://www.gtmweb.com.br/rs-publicados-osindices-de-participacao-dos-municipios-2015-noicms/>. Acesso em: 04 nov. 2015. 